\title{
Erratum to: Urban-rural humidity and temperature differences in the Beijing area
}

\author{
Weidong Liu $\cdot$ Huanling You $\cdot$ Junxia Dou
}

Published online: 9 December 2009

(C) Springer-Verlag 2009

\section{Erratum to: Theor Appl Climatol (2009) 96:201-207 DOI 10.1007/s00704-008-0024-6}

In the original article some data, a table and some figures were unfortunately incorrect.

The corrections are as follows:

1. Abstract, line 19, "1.5475 hpa" should be "0.213 hpa". 2. Section 1, the first paragraph, line 54, "Wilhelm et al. (2007)" should be "Kuttler et al. (2007)".

3. Table 4 should be:

\begin{tabular}{|c|c|c|c|c|c|c|}
\hline & \multirow[t]{2}{*}{ Period } & \multicolumn{4}{|l|}{ Time } & \multirow[b]{2}{*}{ Average } \\
\hline & & 0200 & 0800 & 1400 & 2000 & \\
\hline \multirow[t]{3}{*}{$\left.\mathrm{e}_{\text {Beijing }} \mathrm{hpa}\right)$} & 1971-1980 & 10.693 & 10.739 & 10.516 & 11.403 & 10.837 \\
\hline & 1981-1996 & 10.662 & 10.373 & 9.866 & 10.715 & 10.404 \\
\hline & $1997-2003$ & 11.168 & 10.951 & 10.371 & 11.274 & 10.941 \\
\hline \multirow[t]{3}{*}{$\mathrm{e}_{\text {Miyun }}$ (hpa) } & 1971-1980 & 10.500 & 10.242 & 9.859 & 10.881 & 10.370 \\
\hline & 1981-1996 & 10.588 & 10.544 & 10.210 & 11.126 & 10.617 \\
\hline & $1997-2003$ & 10.772 & 10.725 & 10.046 & 11.103 & 10.661 \\
\hline \multirow{3}{*}{$\begin{array}{l}\Delta \mathrm{e}\left(\mathrm{e}_{\text {Beijing }} \mathrm{-}_{\mathrm{Miyun}}\right) \\
\text { (hpa) }\end{array}$} & 1971-1980 & 0.193 & 0.497 & 0.657 & 0.522 & 0.467 \\
\hline & 1981-1996 & 0.074 & -0.171 & -0.344 & -0.411 & -0.213 \\
\hline & $1997-2003$ & 0.395 & 0.226 & 0.325 & 0.171 & 0.279 \\
\hline
\end{tabular}

The online version of the original article can be found at http://dx.doi. org/10.1007/s00704-008-0024-6.

\footnotetext{
W. Liu $\cdot$ J. Dou

Institute of Urban Meteorology,

No. 55 Beiwaxili Road, Haidian District,

100089 Beijing, China

W. Liu $(\bowtie) \cdot$ J. Dou

Institute of Urban Meteorology, Beijing,

Chinese Meteorological Administration (CMA),

100089 Beijing, China

e-mail:wdliu@ium.cn

H. You

Beijing Weather Information Service,

100089 Beijing, China
}

4. Fig. 4 should be:

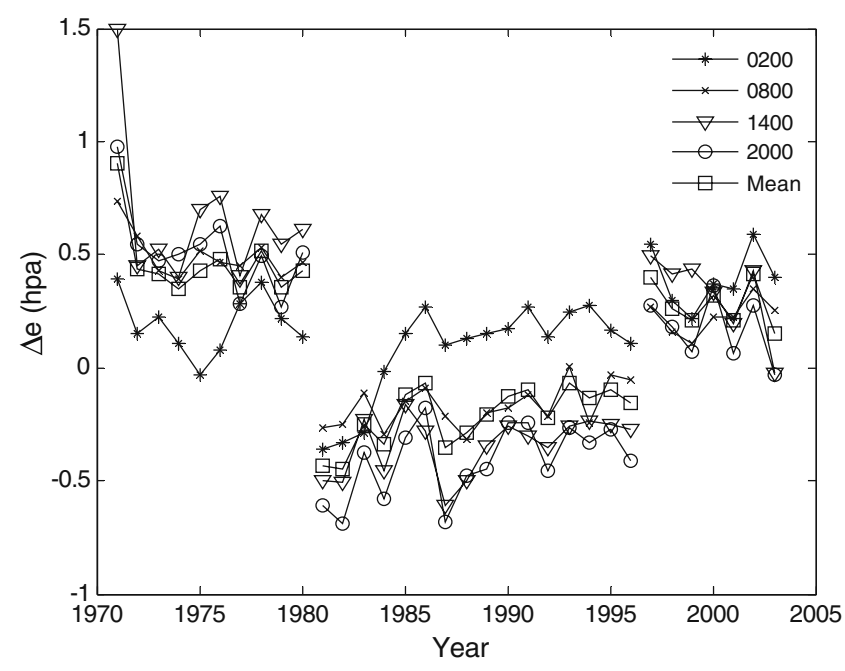

5. Fig. 8 should be:

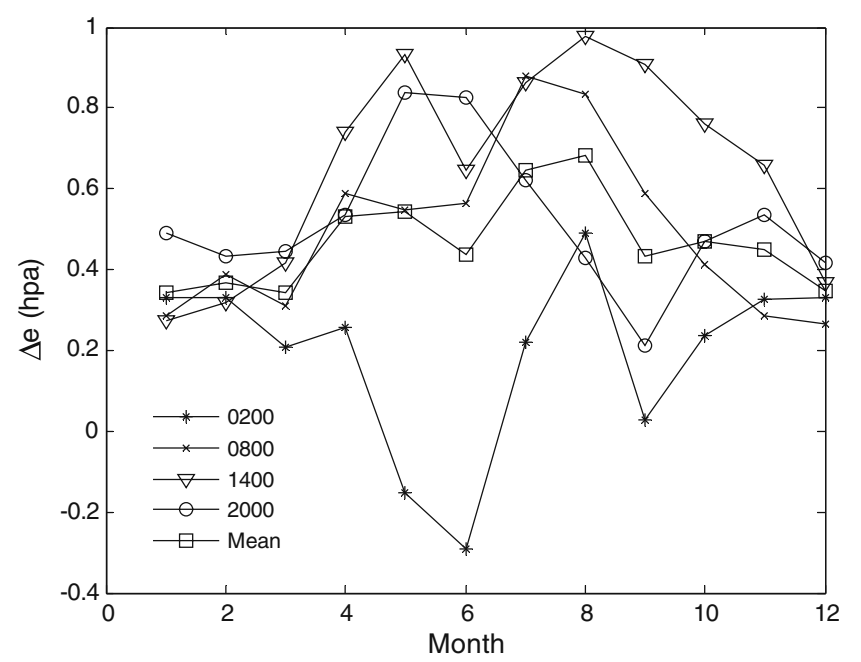


6. Fig. 9 should be:

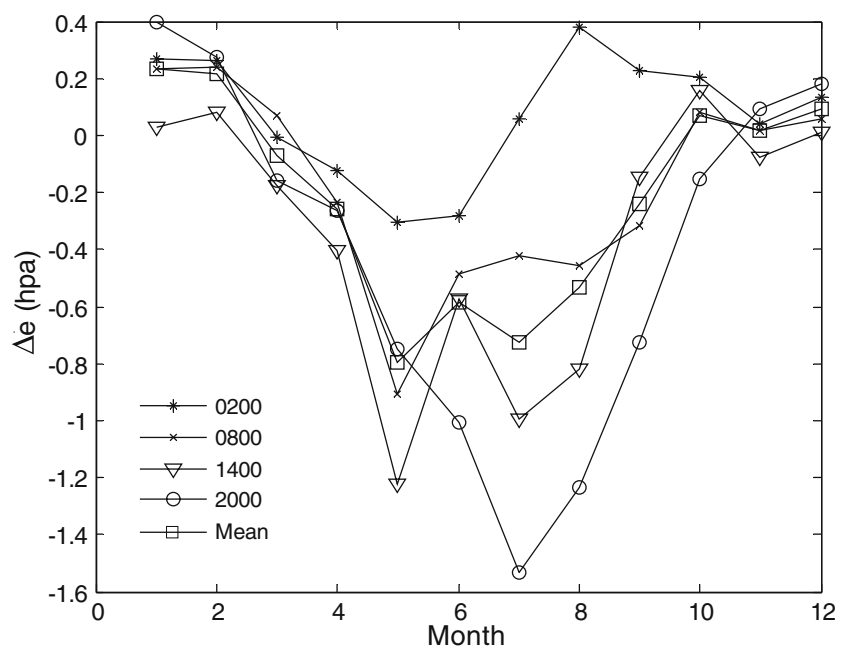

7. Fig. 10 should be:

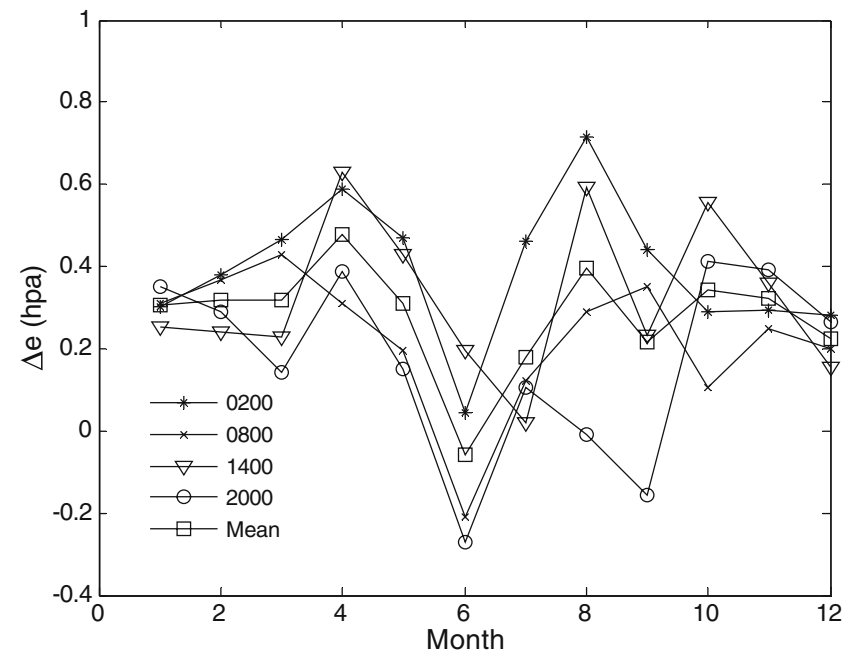

8. Section 4 , the first paragraph, line 17 , the sixth words "0.74 hpa" should be "0.074 hpa". 